\title{
Return to play? Athletes with congenital long QT syndrome
}

\author{
Jonathan N Johnson, ${ }^{1}$ Michael J Ackerman ${ }^{1,2,3}$
}

\begin{abstract}
- Additional supplementary tables are published online only. To view these files please visit the journal online (http:// dx.doi.org/10.1136/bjsports2012-091751)

1 Department of Pediatrics/ Division of Pediatric Cardiology, Mayo Clinic, Rochester, Minnesota, USA 2Department of Medicine/ Division of Cardiovascular Diseases, Mayo Clinic, Rochester, Minnesota, USA ${ }^{3}$ Department of Molecular Pharmacology \& Experimental Therapeutics, Windland Smith Rice Sudden Death Genomics Laboratory, Mayo Clinic, Rochester, Minnesota, USA
\end{abstract}

\section{Correspondence to Dr Michael J Ackerman, Department of Molecular Pharmacology \& Experimental Therapeutics, Long QT Syndrome Clinic and the Mayo Clinic, Windland Smith Rice Sudden Death Genomics Laboratory, Mayo Clinic, Guggenheim 501, 200 First Street SW, Rochester, MN 55905, USA; \\ ackerman.michael@mayo.edu}

Received 6 September 2012 Revised 6 September 2012 Accepted 6 October 2012 Published Online First 28 November 2012
To cite: Johnson JN, Ackerman MJ. Br I Sports Med 2013, 47, 28-33

\section{ABSTRACT}

Background Competitive sports participation for athletes with congenital long QT syndrome (LQTS) is guided by the 2005 36th Bethesda Conference and the 2005 European Society of Cardiology (ESC) guidelines. The purpose of this study was to determine the prevalence and outcomes of patients with LQTS who chose to remain athletes following their diagnosis. Methods Records of all patients between 6 and 40 years of age who were first evaluated in Mayo Clinic's LQTS Clinic from July 2000 to November 2010 were reviewed, for documentation of athletic participation after LQTS diagnosis and LQTS-related events during follow-up. Average follow-up was $5.5 \pm 3.4$ years.

Results The cohort included 353 patients with LQTS (199 females, mean age 17 \pm 11 years, mean QTc 472 $\pm 42 \mathrm{~ms}$ ), of whom 182 had LQT1, 130 had LQT2, 37 had LQT3 and 4 had multiple LQTS mutations. The majority of patients $(223,63 \%)$ were either not involved in sports (88\%) or chose to discontinue sports (12\%) following evaluation. 130 patients (37\%, 60 females, mean age $11 \pm 7$ years, mean QTc $471 \pm 46 \mathrm{~ms}$ ) remained in competitive athletics, including 20 with implantable cardioverter defibrillators (ICDs). Of these 130, 70 (54\%) were genotype-positive/phenotype-negative and competing contrary to ESC guidelines but within the Bethesda guidelines. None of these athletes had a sportrelated event. Of the 60 LQTS athletes continuing in sports contrary to both the Bethesda and ESC guidelines (genotype-positive/phenotype-positive), only one had a sporting-related event with appropriate ICD shock. Conclusions Athletes and their families are fully capable of self-disqualification. Among those athletes with LQTS who chose to remain in competitive sports, a low rate of cardiac events and no deaths were observed in over 650 athlete-years of follow-up. Current guidelinebased recommendations for disqualification may be excessive for this disease.

\section{INTRODUCTION}

Congenital long QT syndrome (LQTS) affects 1 in 2000 persons and was first described as the Jervell and Lange-Nielsen syndrome and Romano-Ward syndrome in the late $1950 \mathrm{~s} /$ early $1960 \mathrm{~s}^{1-4}$ The trademark and potentially lethal ventricular arrhythmia underlying the symptomatic LQTS patient is torsades de pointes (TdP). ${ }^{5}$ LQTS may present with syncope, seizures or sudden death. ${ }^{5}$ To date, 13 distinct LQTSsusceptibility genes have been discovered. However, mutations in the three most common LQTS subtypes: KCNQ1-mediated LQT1, KCNH2-mediated LQT2 and SCN5A-mediated LQT3, account for $75 \%$ of clinically definite LQTS. ${ }^{6-9}$

The risk of having a cardiac event in patients with LQTS is dependent on the specific genotype and mutation involved, the age and gender of the patient and degree of abnormal repolarisation. ${ }^{10-13}$ Data from the International LQTS Registry has demonstrated a specific effect of age and gender on childhood event rates. ${ }^{10}$ Prior to age 13 , males with LQT1 have the highest event rates, whereas after the age of 13, females with LQT2 have the highest event rates. Considering the spectrum of LQTS risk profiles, the risk of an LQTS-triggered cardiac event ranges from $0.5 \%$ to $10 \%$ per year with overall event rates lowest in children who had a QTc $<500 \mathrm{~ms}$ and no history of syncope regardless of gender. ${ }^{10}$ The addition of $\beta$-blockers significantly reduces the risk of aborted cardiac arrest (ACA) and sudden cardiac death in children with LQTS, particularly in patients with a history of syncope. ${ }^{10} 12$

In the USA, competitive sports participation for patients with LQTS is guided by the 2005 36th Bethesda Conference guidelines. ${ }^{14}$ In the same year, the European Society of Cardiology (ESC) published their guidelines. ${ }^{15}$ Both the Bethesda and the ESC guidelines recommend disqualification from virtually every competitive sport (other than Bethesda-permitted class IA sports which include only billiards, bowling, cricket, curling, golf and riflery) for any patient with LQTS-related symptoms (Bethesda recommendation \#1), as well as any asymptomatic patient with electrocardiographically manifest LQTS (Bethesda recommendation \#2, table 1). However, the guidelines differed markedly regarding their recommendations for the asymptomatic, genotype-positive/phenotypenegative patient with the Bethesda guidelines allowing participation (except for LQT1 patients and swimming, Bethesda recommendation \#3), while the ESC advises disqualification from competitive athletics. ${ }^{14}{ }^{15}$ Both sets of guidelines also advised disqualification for any athlete with an implantable cardioverter defibrillator (ICD) from all non-class IA sports (Bethesda recommendation \#4). ${ }^{14} 15$

While fully respecting these guidelines and participating in the Bethesda conference guidelines as a coauthor (MJA), we have embraced the tenets of self-determination and patient/family autonomy in our LQTS/Genetic Heart Rhythm Clinic and recognise and respect the athletes and his/her family's right to make a well-informed, risk-benefit decision regarding the continuation of athletics. Consequently, we considered it critical to evaluate the impact of this approach, to determine whether it resulted in universal sports participation, and to assess whether or not a determination to stay and play translated into an unacceptable risk exposure. Hence, in this study we sought to determine the prevalence and outcomes of children and young 
Table 1 Current published guidelines regarding competitive sports and the athlete with LQTS

\begin{tabular}{|c|c|}
\hline 2005 Bethesda Conference guidelines & 2005 ESC guidelines \\
\hline $\begin{array}{l}\text { Patients who have a history of } \\
\text { LQTS-related symptoms, have a QTC } \\
>470 \text { ms (males) or }>480 \text { ms (females) } \\
\text { or who have an ICD should be limited to } \\
\text { Class IA sports }\end{array}$ & $\begin{array}{l}\text { All patients who have LQTS, } \\
\text { symptomatic or asymptomatic, are } \\
\text { disqualified from all competitive } \\
\text { sports }\end{array}$ \\
\hline $\begin{array}{l}\text { Asymptomatic genotype-positive/ } \\
\text { phenotype-negative patients are allowed } \\
\text { to play, but are not at zero-risk* }\end{array}$ & $\begin{array}{l}\text { Recommended using QTc values of } \\
>440 \mathrm{~ms} \text { (males) or }>460 \mathrm{~ms} \\
\text { (females) as a trigger for further } \\
\text { evaluation }\end{array}$ \\
\hline
\end{tabular}

adults with LQTS who chose to remain athletes following their diagnosis.

Noteworthy is that a summary of this dataset was published previously in the Journal of the American Medical Association as a brief report, however, many important details were not included due to space constraints. ${ }^{16}$ Here, we present the full dataset for analysis.

\section{METHODS}

\section{Study design}

After obtaining Institutional Review Board approval, we performed a retrospective review of patients seen in the Mayo Clinic LQTS Clinic between July 2000 and November 2010 who were between the ages of 6 and 40 years at the time of their initial evaluation at our institution (the years of the 'highest' potential athletic activity) and who had LQT1, LQT2, LQT3 or multiple mutation LQTS. Blinded to genotype, we reviewed the electronic medical record for demographic variables and clinical history. Records were reviewed for documentation of athletic participation after LQTS diagnosis and LQTS-related events including syncope, seizures, documented ventricular arrhythmias, ACA or sudden death. If the patient was not an athlete, we determined whether this was due to the patient having stopped athletics after their LQTS diagnosis and evaluation at our centre, or due to the patient not being involved in athletics before or after diagnosis. If a patient had an ICD, we reviewed all interrogation records for evidence of appropriate discharges.

We considered a 'competitive athlete' to be an athlete who was participating in organised competitive sports at the professional, college, high-school, middle-school or youth level. All included sports were classified using the Bethesda system for sports classification of 'static' and 'dynamic' components. ${ }^{17}$ If a patient participated in multiple sports, we used their highest classified sport for analysis, ranking them by their 'static' component primarily and secondarily by their 'dynamic' component (ie, if a patient was in both IIA and IB sports, we considered them a IIA-sports participant for analysis). Due to the high static component involved, we considered patients participating in competitive dancing and competitive cheerleading as competitive athletes. These patients were included in the IIIA-sport classification along with gymnastics and martial arts. ${ }^{17}$ The level of competition for each patient was categorised as professional, collegiate, adult competitive (amateur), high school or child competitive (including youth leagues, city leagues and travel leagues) or 'other' if the specific level was unavailable.

If an LQTS athlete had been seen after 1 July 2011, in Mayo's LQTS Clinic for a subsequent follow-up clinical evaluation, we took the date of that follow-up clinical evaluation as time of last follow-up. If their last clinical follow-up visit preceded 1 July 2011, we contacted them by telephone using an IRB-approved script to obtain updated follow-up information. Requested information on telephone follow-up included whether or not the patient continued to participate in competitive athletics, the specific sports and history of any breakthrough cardiac events during or outside of sports. No patients were lost to follow-up.

QTc values were measured manually from a 12-lead ECG and calculated using the standard Bazett's formula. ${ }^{18}$ Whenever possible, leads II or V5 were used for QT interval measurement. All continuous variables were reported as the mean \pm SD. Means were analysed using the independent groups $t$ test for means. A two-tailed $\mathrm{p}$ value $<0.05$ was considered to be significant. Due to the relative retrospective nature of this cohort, event rates for each cohort (non-athlete, athlete and athlete with ICD) were not compared.

\section{LQTS clinic evaluation and philosophy}

Given the Bethesda guidelines' self-admission that the guidelines lacked evidence but were instead grounded in the 'art of medicine', our LQTS clinic embraced the importance of patient/ family autonomy and respect for their right to make a wellinformed decision regarding continuation of athletics. However, knowing that a well-informed decision could still precipitate a premature and tragic death, we also implemented an overarching sudden death safety net strategy to 'be prepared'.

First, the initial LQTS evaluation is a 2-day to 3-day evaluation that includes electrocardiography on two consecutive days, echocardiography if not previously performed, $24 \mathrm{~h}$ ambulatory monitoring, treadmill exercise testing, pharmacological (epinephrine, lidocaine or procainamide) stress testing if indicated, genetic counselling and genetic testing if indicated, and additional consultations with psychology/psychiatry, an ICD implant specialist and/or a surgeon specialising in left cardiac sympathetic denervation (LCSD) if needed. This primary evaluation culminates with a $1-2 \mathrm{~h}$ consultation with an LQTS specialist (MJA) to discuss the diagnostic, prognostic and therapeutic implications of their LQTS.

Independent of their athletic status, a treatment plan is implemented according to the LQTS specialist's perceived risk of their disease. Most patients (athletes and non-athletes) return for an annual or alternate year 1-2 day follow-up evaluations where their risk profiles and treatment programmes are reassessed.

If the patient was an athlete at the time of their Mayo Clinic evaluation, extensive counselling is provided to discuss how their present diagnosis and clinical presentation squares with the published guidelines regarding their continued participation. The family is provided a copy of the Bethesda Conference guidelines. In addition, their decision to remain an athlete is reviewed at each follow-up visit and the athlete and his/her family are informed of any updates in our clinic's experience or the published literature regarding the risk of their decision including being informed of our singular LQTS athlete who received a VF-terminating ICD shock during a sport. These extensive face-to-face consultations at their primary and follow-up evaluations are necessary to ensure that the athlete and his/her family are 'well informed'. 
Second, if both parents are involved in the care of the young paediatric athlete, then all three of the family members (the athlete and both of his/her parents) must agree to allow athletic participation. If even a single family member objects for safety concerns, then the athlete is disqualified.

Third, independent of their athlete status, we risk stratify and treat according to that assessed/perceived risk of an LQT-triggered cardiac event. We require that any patient participating contrary to Bethesda guidelines be protected with the best evidence-based therapy possible. This most often entails the use of $\beta$-blocker medications, particularly in LQT1 or LQT2. If the patient has $\beta$-blocker intolerance, an LCSD may be performed. QT drug avoidance (http://www.qtdrugs.org), proper hydration, replenishment of electrolytes and minimisation of elevations in core body temperature are advised. ICD placement was recommended on a case-by-case basis. Common indications for ICD placement included: secondary prevention in cases of prior aborted cardiac arrest, medication intolerance or breakthrough, and primary prevention in high-risk patients (patients with Jervell-Lange Nielsen syndrome, infants with 2:1 atrioventricular block, LQT2 females with QTc >500 ms and non-LQT1 patients with QTc >550 ms). Importantly, an ICD recommendation was independent of the LQTS patient's athlete/non-athlete status.

Finally, each LQTS athlete is instructed to acquire his/her own automatic external defibrillator (AED) as part of their overall sports gear, akin to the peanut allergy athlete and his/her epi-pen or the diabetic athlete and his/her sugar pill. In addition, the school officials, coaches and other supervisors must be informed and must agree with this plan. We advise personal acquisition of an AED rather than reliance on a school-based AED out of an abundance of precaution. An AED is not required for most patients who already have an ICD in place, however, emphasis is placed on the usual LQTS safety measures (QT drug avoidance (http://www.qtdrugs.org), proper hydration, replenishment of electrolytes and minimisation of elevations in core body temperature).

\section{RESULTS}

From July 2000 through November 2010, 353 patients between 6 and 40 years of age with genetically confirmed LQTS were evaluated (199 females, average age at diagnosis $17 \pm 11$ years, average QTc $472 \pm 42 \mathrm{~ms}$, table 2). Of these, 196/353 patients

Table 2 Demographics of overall cohort

\begin{tabular}{llll}
\hline & Total cohort & Athletes & Non-athletes \\
\hline Number of patients & 353 & 130 & 223 \\
Age at diagnosis (years) & $17 \pm 11$ & $11 \pm 7$ & $20 \pm 12$ \\
Sex (male/female) & $154 / 199$ & $70 / 60$ & $84 / 139$ \\
Average QTc (ms) & $472 \pm 42$ & $471 \pm 46$ & $472 \pm 39$ \\
Genotype & & & \\
$\quad$ LQT1 & $182(52 \%)$ & $74(57 \%)$ & $108(48 \%)$ \\
LQT2 & $130(37 \%)$ & $41(32 \%)$ & $89(40 \%)$ \\
LQT3 & $37(10 \%)$ & $11(8 \%)$ & $26(12 \%)$ \\
$\quad$ Multiple & $4(1 \%)$ & $4(3 \%)$ & $0(0 \%)$ \\
Symptoms & $111(31 \%)$ & $29(22 \%)$ & $82(37 \%)$ \\
$\beta$-Blockers & $280(79 \%)$ & $112(87 \%)$ & $168(75 \%)$ \\
ICD & $78(22 \%)$ & $20(15 \%)$ & $58(26 \%)$ \\
Follow-up available (years) & $5.5 \pm 3.4$ & $5.1 \pm 2.9$ & $5.8 \pm 3.7$ \\
\hline
\end{tabular}

Ages, QTc at diagnosis and follow-up are reported as mean \pm SD.

ICD, implantable cardioverter defibrillators; LQT, long QT.
$(56 \%)$ were not participating in athletics at the time of their first evaluation. Of the 157 athletes, 27 (17\%) chose to discontinue competitive athletics following their evaluation while $130(83 \%)$ elected to continue with sports participation. There were no significant differences in the demographics or LQTS risk factors between the athletes who elected for self-disqualification and those who chose to remain an athlete.

\section{LQTS athletes}

Among the 130 patients (60 females, mean age $11.5 \pm 7$ years, mean QTc $471 \pm 46 \mathrm{~ms}$, mean length of follow-up $=5.1$ \pm 2.9 years, median $=4.4$ years, $\mathrm{IQR}=2.73-6.49$ years) who remained engaged in competitive athletics following their diagnosis of LQTS and 2-3 day LQTS evaluation at our centre, 112 $(86 \%)$ were treated with $\beta$-blockers, $21(16 \%)$ had an LCSD and $20(15 \%)$ had an ICD (see online supplemental tables S1 and S2). LQT1 was the most common genotype accounting for $74 / 130(57 \%)$ of athletes, followed by LQT2 (41/130, 32\%), LQT3 (11/130, 8\%) and patients with multiple mutations $(4 / 130,3 \%)$. In total 130 athletes competed in a wide array of competitive sports across all Bethesda sports classifications (figure 1). The most common sports were basketball (class IIC, $\mathrm{N}=27$ ), competitive cheerleading/dance/gymnastics (class IIIA, $\mathrm{N}=16$ ), soccer (class IC, $\mathrm{N}=15$ ), baseball/softball (class $\mathrm{IB}$, $\mathrm{N}=14$ ), volleyball (class $\mathrm{IB}, \mathrm{N}=8$ ) and football (class IIB, $\mathrm{N}=7$ ). Further, 49 of the 130 athletes (38\%) were participating in more than one sport.

\section{Bethesda guidelines}

While all 130 LQTS athletes were participating contrary to the ESC sports participation guidelines, there were 70 (54\%, 29 females, average age at diagnosis $11 \pm 7$ years, average QTc $444 \pm 23 \mathrm{~ms}$ ) whose participation was still in accordance with the Bethesda guidelines. Three of these 70 patients were participating in accordance with limitations of LQTS patients to class 1A sports, all three participating in golf. The remaining $67 / 70$ $(96 \%)$ were participating under recommendation \#3, where genotype-positive/phenotype-negative patients were permitted to participate in all sports (other than the stated recommendation against competitive swimming for patients with LQT1).

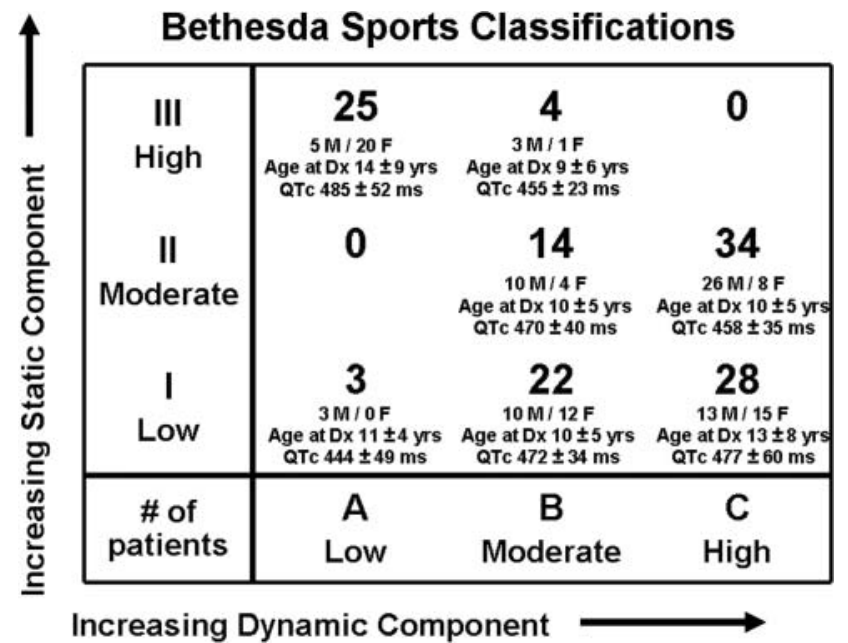

Figure 1 Classification of primary sport for the patients who chose to remain in athletics. The classifications are listed in order of published static component (Classes I-III) and dynamic components (Classes A-C). Dx, diagnosis. 
The remaining 60 LQTS athletes $(46 \%, 31$ females, average age at diagnosis $12 \pm 7$ years, average QTc $501 \pm 46 \mathrm{~ms}$ ) were participating contrary to both the ESC and the Bethesda guidelines. This included all 20 patients participating with ICDs, as athletic participation with an ICD in place was contrary to Bethesda recommendation \#4. Nearly half $(28 / 60,47 \%)$ of this subset had a history of LQTS-related symptoms, and 57/60 (95\%) were treated with $\beta$-blockers. The three patients not treated with $\beta$-blockers included two male patients with LQT3 (diagnosed at 16 and 2 years, respectively) and an 11-year-old LQT1 male who had LCSD because of $\beta$-blocker intolerance. Of the 60 patients, 13 were participating contrary to only recommendation \#1 (previously symptomatic LQTS), 26 to only recommendation \#2 (asymptomatic but ECG-manifest LQTS), 1 to only recommendation \#3 (a teenage girl with LQT1 who was a competitive swimmer) and 2 to only recommendation \#4 (genotype-positive/phenotype-negative but presence of an ICD). There were 18 athletes participating contrary to multiple recommendations.

There were several significant differences noted between the subsets of patients participating against ESC but within the Bethesda and those participating against both guidelines (table 3). Expectedly, those participating within the Bethesda were far less likely to be symptomatic $(\mathrm{p}<0.0001)$, had lower baseline QTc values $(p<0.0001)$ and were less likely to be treated with $\beta$-blockers.

\section{Level of competition}

The level of competition for the subset of LQTS athletes is listed in table 4 . There were a large proportion of the athletes who were competing in paediatric age competitive sports, including 57\% in either city, travel or youth leagues, and a further $25 \%$ at the high-school level. There were eight patients competing at the national or college level.

\section{LQTS, athletes and ICDs}

Among the 20 LQTS athletes with ICDs (11 females, average age at diagnosis $14.5 \pm 9$ years, average QTc $520 \pm 65 \mathrm{~ms}$, LQT1

Table 3 Demographics of athlete participation relative to the Bethesda and ESC guidelines

\begin{tabular}{|c|c|c|c|}
\hline & $\begin{array}{l}\text { Against ESC but } \\
\text { within Bethesda }\end{array}$ & $\begin{array}{l}\text { Contrary to both } \\
\text { ESC and Bethesda }\end{array}$ & $\begin{array}{l}p \\
\text { Value }\end{array}$ \\
\hline Number of patients & 70 & 60 & \\
\hline $\begin{array}{l}\text { Age at diagnosis } \\
\text { (years) }\end{array}$ & $11 \pm 7$ & $12 \pm 6$ & NS \\
\hline Sex (male/female) & $41 / 29$ & $29 / 31$ & NS \\
\hline Average QTc (ms) & $444 \pm 23$ & $501 \pm 46$ & $<0.0001$ \\
\hline \multicolumn{4}{|l|}{ Genotype } \\
\hline LQT1 & $41(59 \%)$ & $33(55 \%)$ & NS \\
\hline LQT2 & $20(29 \%)$ & $21(35 \%)$ & NS \\
\hline LQT3 & $8(11 \%)$ & $3(5 \%)$ & NS \\
\hline Multiple & $1(1 \%)$ & $3(5 \%)$ & NS \\
\hline History of symptoms & $1(1 \%)$ & $28(47 \%)$ & $<0.0001$ \\
\hline$\beta$-Blockers & $55(79 \%)$ & $57(95 \%)$ & $<0.008$ \\
\hline ICD & 0 & $20(33 \%)$ & $<0.0001$ \\
\hline $\begin{array}{l}\text { Follow-up available } \\
\text { (years) }\end{array}$ & $5.1 \pm 2.9$ & $5.0 \pm 3.0$ & NS \\
\hline
\end{tabular}

Ages, QTc at diagnosis and follow-up are reported as mean \pm SD.

ESC, European Society of Cardiology; ICD, implantable cardioverter defibrillators; LQT, long QT.
Table 4 Level of competition

\begin{tabular}{llll}
\hline $\begin{array}{l}\text { Level of } \\
\text { competition } \\
\text { (N=130) }\end{array}$ & $\begin{array}{l}\text { Number of } \\
\text { patients in total } \\
\text { cohort } \\
(\% \text { of total) }\end{array}$ & $\begin{array}{l}\text { Against ESC } \\
\text { but within } \\
\text { Bethesda } \\
\mathbf{N}=70\end{array}$ & $\begin{array}{l}\text { Contrary to } \\
\text { both ESC and } \\
\text { Bethesda } \\
\mathbf{N}=60\end{array}$ \\
\hline National/professional & $1(1 \%)$ & $0(0 \%)$ & $1(2 \%)$ \\
College & $7(5 \%)$ & $6(9 \%)$ & $1(2 \%)$ \\
$\begin{array}{l}\text { Adult competitive } \\
\text { High school }\end{array}$ & $11(8 \%)$ & $4(6 \%)$ & $7(12 \%)$ \\
City, travel, and & $32(25 \%)$ & $16(23 \%)$ & $16(27 \%)$ \\
youth league & $74(57 \%)$ & $40(57 \%)$ & $34(57 \%)$ \\
Other & $5(4 \%)$ & $4(6 \%)$ & $1(2 \%)$ \\
\hline ESC, European Society of Cardiology. & &
\end{tabular}

in 5, LQT2 in 11, LQT3 in 3 and compound LQT1/LQT2 in 1), 15 were previously symptomatic, most commonly syncope, ventricular tachycardia or ventricular fibrillation. $\beta$-Blockers were being taken by $18 / 20$ athletes with an ICD; the sole athletes abstaining from $\beta$-blockers were two young males with LQT3. These ICD-positive athletes were participating in a wide variety of sports, including six in Bethesda class III sports, six in class II sports and eight in class IB/IC sports.

\section{LQT-triggered cardiac events among athletes}

Regardless of athlete status, there have been no deaths in this cohort. In addition, there have not been any more LQT-triggered cardiac events among the athletes, on or off the athletic field, compared to the 223 patients with LQTS who were not participating in competitive sports (data not shown). No athlete competing at the national or collegiate level has had an event. In fact, there has been only one athlete $(<0.8 \%)$ who has experienced two competitive sporting-related events in a combined total of approximately 650 athlete-years of follow-up. This boy was 1 of the 60 LQTS athletes continuing in sports contrary to both the ESC and the Bethesda guidelines. He was a previously symptomatic 9-year-old patient with LQT1, extreme QT prolongation (QTc at diagnosis at age 7 was $490 \mathrm{~ms}$, QTc at follow-up $>550 \mathrm{~ms}$ ), and a history of VF-resuscitated, aborted cardiac arrest. He has now received two appropriate VF-terminating ICD shocks; the first occurred while preparing to play in a soccer game and the second occurred while warming up before a baseball game. Each event occurred in the setting of admitted non-compliance with $\beta$-blocker medication.

\section{DISCUSSION}

Current published guidelines in the USA and Europe advise disqualification from athletic participation of many patients with LQTS. ${ }^{14}{ }^{15}$ Here, we present the largest published cohort of athletes with LQTS who have chosen to remain engaged in competitive sports and observed only one athlete experiencing two LQT-related cardiac events during athletics in over 650 athlete-years of follow-up.

\section{Athletes}

When allowed the choice of participation, it is clear that many patients, particularly those still in school in the paediatric age ranges, will choose to remain active in competitive sports. Interestingly, of all 130 patients who chose to continue competitive athletics, only 3 of them were participating in class IA sports, which all would have otherwise been limited to by the Bethesda guidelines. When given the choice, very few patients 
will choose only to participate in billiards, bowling, cricket, curling, golf or riflery. ${ }^{17}$ This has clear implications in the current era where obesity rates in children continue to rise despite many attempted preventative measures. ${ }^{19}{ }^{20}$ A pure restriction from athletics can have dire consequences in any patient cohort, and absolute avoidance of all aerobic activity should be discouraged. ${ }^{21}$

\section{Bethesda and ESC guidelines}

In this study, 60/130 (46\%) patients who chose to continue competitive athletics after their LQTS diagnosis did so contrary to the most recent Bethesda guidelines. This included 20 patients who had an ICD in place and 28 who had a history of LQTS-related symptoms. Despite this, only one high-risk young man with a very striking history suffered a sporting-related event.

At minimum, these findings would seem to necessitate revisiting both the ESC and Bethesda guidelines regarding athletic participation in patients with LQTS. The current ESC restriction of even genotype-positive/phenotype-negative individuals appears excessively restrictive, as we did not have a single event in this cohort of patients despite participation in a wide variety of sports. ${ }^{15}$ Unfortunately, the disqualification of athletes with LQTS in Europe has become routine (and in fact the law) in some countries. There were no athletic-related events noted in our LQT3 cohort, which would support the Bethesda guideline's relaxation of restrictions for asymptomatic LQT3 patients. ${ }^{14}$

In this study, we have not yet observed any ICD-related complications among our 20 ICD patients who chose to continue competitive athletics, although such complications have been reported previously. ${ }^{22}$ Potential risks may include the damage to the device or leads during repetitive motion of the arms, particularly during weight-lifting, golf and tennis. Interestingly, golf is one of the few sports permitted under the Bethesda guidelines for LQTS patients with an ICD. This issue requires further evaluation, and more data should emerge from the ongoing ICD Sports Registry (http://www.ICDsportsregistry.org).

\section{Patient/family autonomy}

Given the Bethesda guidelines' self-admission that the guidelines lacked evidence but were instead grounded in the 'art of medicine', our LQTS clinic has embraced the importance of patient/ family autonomy and respect for their right to make a wellinformed decision regarding continuation of athletics. Contrary to popular belief, this approach does not result in universal sports participation. As we observed, presented with the same risk-benefit information, nearly one of every five athletes and their families chose disqualification.

Anecdotally, we have seen more events occur in patients who were either not involved in athletics or who chose selfdisqualification, compared to those who have continued in athletics. This statistically cannot be compared due to retrospective nature of the study, and the vastly heterogenous populations described. However, it is intriguing to speculate that participation in athletics may have a 'protective' effect in young LQTS patients. This may be due in part to the acknowledgment of responsibility that comes with being granted this form of autonomy. For instance, due to our insistence on certain parameters prior to participating, our athletes may have a better compliance with medication dosing and electrolyte replacement than our non-athletes. In our study, no athlete had a cardiac event when optimally managed with $100 \%$ coverage by $\beta$-blockers, LCSD or ICD. This potential and seemingly paradoxical 'protective' effect of athletics in young LQTS patients warrants further study.
What are the new findings?

- In a cohort of 130 athletes with long QT syndrome (LQTS) who continued to participate in competitive athletics following their diagnosis, only one had a cardiac event in over 650 athlete-years of follow-up.

- One patient with an event was a known high-risk 9-year-old LQT1 male with a history of cardiac arrest and implantable cardioverter-defibrillator (ICD) placement, who received two appropriate ICD therapies, both while warming up prior to practices, and both during admitted non-compliance with $\beta$-blocker medication.

- Current guidelines for competitive athletic participation, particularly those disqualifying genotype-positive/ phenotype-negative patients (the European Society of Cardiology guidelines), may be excessive for this disease.

- Comprehensive evaluation, counselling, risk stratification, medical management and preparation must take place prior to allowing LQTS athletes to continue competitive athletics after their diagnosis.

\section{How might it impact clinical practice in the near future?}

- This study could stimulate discussion about the roles of the physician, the athlete and the family in decision-making regarding return-to-play issues.

- Regarding patients with long QT syndrome (LQTS), this study should help move the 'goal posts' regarding patient management. The goal should no longer be the prevention of sudden death. Rather, it should be directed to living and thriving despite the diagnosis.

- These observations should stimulate re-examination of the most recent 2005 expert opinion guidelines from both sides of the Atlantic (the Bethesda Conference guidelines in North America and the European Society of Cardiology guidelines in Europe) regarding sports participation in athletes with LQTS.

\section{Limitations}

Importantly, our data applies only to athletes with LQTS and cannot be extrapolated to other genetic channelopathies and cardiomyopathies where the guidelines currently recommend restriction from athletics. Whether the event rate would be as low for other genetic heart diseases as observed in our cohort of athletes with LQTS requires further study. Further, in our dataset, some sports classifications have very limited participation (especially class IIIB and IIIC sports), and extrapolation of our findings to sports in these classifications may be premature. In addition, we limited our patient selection to those between the ages of 6 and 40, and thus outcomes of athletic participation in patients over 40 years of age are unable to be determined from this study. Considering that a guideline-based recommendation for disqualification has been in place for almost 20 years, it is not surprising that our athletic cohort was skewed towards younger patients with only eight patients in the athletic cohort over the age of 21. As such, athletic outcomes in adults with LQTS warrant further investigations. Finally, the clinical 
outcomes described in this paper can only be examined in the context of our dedicated LQTS Clinic's comprehensive 2-3 day approach regarding a patient's clinical evaluation, assessment and LQTS-directed treatment programme. It is not possible to extrapolate our outcomes to other versions of the LQTS evaluation process without further research.

\section{CONCLUSIONS}

With over 650 athlete-years of follow-up, we report an extremely low rate of cardiac events among LQTS athletes during sports. This suggests that the current guidelines, which relied on 'expert consensus and the art of medicine', may be excessively restrictive for this particular disease and should be revisited. In addition, our experience shows that an approach that embraces patient/ family autonomy and self-determination does not result in universal continuation of sports participation. Importantly, however, the outcomes seen in our LQTS specialty clinic should not be viewed as an unqualified 'free pass' for patients with LQTS. A comprehensive and extensive team approach is needed to meticulously phenotype the patient to ensure that an accurate risk forecast is generated and communicated, and that a robust treatment plan is implemented. Only then can the athlete and his/her family be equipped properly to make a well-informed decision about remaining an athlete, as the parents more than anyone know just how high the stakes are.

Acknowledgements Dr Michael Ackerman's research programme was supported by the Mayo Clinic Windland Smith Rice Comprehensive Sudden Cardiac Death Program. The investigators would like to thank the patients who sought evaluation at the Mayo's LQTS Clinic, as well as Mrs Heidi I Owen, RN, Ms Carla M Haglund and Ms Katy Harris, MS, RN, for their assistance with patient follow-up.

Contributors JNJ and MJA were involved in conception and design, acquisition of data, analysis and interpretation of data, drafting of the manuscript and revisions and final approval.

Funding None.

Competing interests MJA had full access to all the data in the study and is responsible for the integrity of the data and the accuracy of the data analysis. Dr Ackerman is a consultant for Biotronik, Boston Scientific, Medtronic, St Jude Medical, Inc and Transgenomic. Intellectual property derived from MJA's research programme resulted in license agreements in 2004 between Mayo Clinic Health Solutions (formerly Mayo Medical Ventures) and PGxHealth (formerly Genaissance Pharmaceuticals, now recently acquired by Transgenomic). The Mayo Foundation for Medical Education and Research receives royalties from Transgenomic for the intellectual property utilised in their FAMILION LQTS genetic test. However, none of these companies supported this study financially or had any involvement in this study.

Ethics approval Mayo Clinic IRB.

Provenance and peer review Not commissioned; externally peer-reviewed.

\section{REFERENCES}

1 Schwartz PJ, Stramba-Badiale M, Crotti L, et al. Prevalence of the congenital long-QT syndrome. Circulation 2009;120:1761-7.

2 Jervell $A$, Lange-Nielsen $F$. Congenital deaf-mutism, functional heart disease with prolongation of the Q-T interval and sudden death. Am Heart J 1957;54:59-68.

3 Romano C, Gemme G, Pongiglione R. (Rare cardiac arrythmias of the pediatric age. li. Syncopal attacks due to paroxysmal ventricular fibrillation. (Presentation of 1st Case in Italian Pediatric Literature)). La Clin Pediatr 1963;45:656-83.

4 Ward OC. A new familial cardiac syndrome in children. J Ir Med Assoc 1964;54:103-6.

5 Ackerman MJ. Cardiac channelopathies: it's in the genes. Nat Med 2004;10:463-4.

6 Medeiros-Domingo A, Kaku T, Tester DJ, et al. SCN4B-encoded sodium channel beta4 subunit in congenital long-QT syndrome. Circulation 2007;116:134-42.

7 Ueda K, Valdivia C, Medeiros-Domingo A, et al. Syntrophin mutation associated with long QT syndrome through activation of the nNOS-SCN5A macromolecular complex. Proce Natl Acad Sci USA 2008;105:9355-60.

8 Chen L, Marquardt ML, Tester DJ, et al. Mutation of an A-kinase-anchoring protein causes long-QT syndrome. Proc Natl Acad Sci USA 2007;104:20990-5.

9 Tester DJ, Will ML, Haglund CM, et al. Effect of clinical phenotype on yield of long QT syndrome genetic testing. J Am Coll Cardiol 2006;47:764-8.

10 Liu JF, Jons C, Moss AJ, et al. Risk factors for recurrent syncope and subsequent fatal or near-fatal events in children and adolescents with long QT syndrome. J Am Coll Cardiol 2011;57:941-50.

11 Goldenberg I, Horr S, Moss AJ, et al. Risk for life-threatening cardiac events in patients with genotype-confirmed long-QT syndrome and normal-range corrected QT intervals. J Am Coll Cardiol 2011;57:51-9.

12 Goldenberg I, Moss AJ, Peterson DR, et al. Risk factors for aborted cardiac arrest and sudden cardiac death in children with the congenital long-QT syndrome. Circulation 2008;117:2184-91.

13 Goldenberg I, Moss AJ, Bradley J, et al. Long-QT syndrome after age 40. Circulation 2008;117:2192-201.

14 Zipes DP, Ackerman MJ, Estes NA 3rd, et al. Task force 7: arrhythmias. J Am Coll Cardiol 2005;45:1354-63.

15 Pelliccia A, Fagard R, Bjornstad $\mathrm{HH}$, et al. Recommendations for competitive sports participation in athletes with cardiovascular disease: a consensus document from the Study Group of Sports Cardiology of the Working Group of Cardiac Rehabilitation and Exercise Physiology and the Working Group of Myocardial and Pericardial Diseases of the European Society of Cardiology. Eur Heart $J$ 2005;26:1422-45.

16 Johnson JN, Ackerman MJ. Competitive sports participation in athletes with congenital long QT syndrome. JAMA 2012;308:764-5.

17 Mitchell JH, Haskell W, Snell P, et al. Task force 8: classification of sports. J Am Coll Cardiol 2005;45:1364-7

18 Bazett H. An analysis of the time-relations of electrocardiograms. Heart 1920;7:353-70.

19 Kamath CC, Vickers KS, Ehrlich A, et al. Clinical review: behavioral interventions to prevent childhood obesity: a systematic review and metaanalyses of randomized trials. J Clin Endocrinol Metab 2008;93:4606-15.

20 Link MS, Estes NA 3rd. Sudden cardiac death in the athlete: bridging the gaps between evidence, policy, and practice. Circulation 2012;125:2511-6.

21 Paffenbarger RS Jr, Hyde RT, Wing AL, et al. Physical activity, all-cause mortality, and longevity of college alumni. N Engl J Med 1986;314:605-13.

22 Lampert R, Cannom D, Olshansky B. Safety of sports participation in patients with implantable cardioverter defibrillators: a survey of heart rhythm society members. J Cardiovasc Electrophysiol 2006;17:11-5. 